\title{
Effect of $\gamma$-radiation on fowl sperm function in vitro and in vivo
}

\author{
G. J. Wishart and L. A. Dick \\ Agricultural and Food Research Council's Poultry Research Centre, Roslin, Midlothian EH25 9PS, U.K.
}

\begin{abstract}
Summary. Doses of up to $300 \mathrm{~Gy}$ of ionizing radiation had little effect on fowl sperm morphology, ATP content and motility when measured in vitro. Fertility of eggs from hens inseminated with spermatozoa receiving $50 \mathrm{~Gy}$, in terms of post-oviducal development, was less than $4 \%$. However, $35 \%$ appeared 'fertile' by macroscopic examination of the germinal disc of unincubated eggs. These contained few embryonic cells, although the vitelline membrane contained many trapped spermatozoa. After doses of $100 \mathrm{~Gy}$ or more, inseminated spermatozoa were not found in the vitelline membrane and no fertile or apparently fertile eggs were produced; nor did such spermatozoa enter the utero-vaginal sperm-host glands.

Genetic transformation using fowl spermatozoa irradiated with doses in excess of $100 \mathrm{~Gy}$ appears to be an unlikely prospect.
\end{abstract}

\section{Introduction}

Pandey \& Patchell (1982) reported that genetic transformation of egg and feather colour was achieved in the domestic fowl by the use of irradiated spermatozoa. They proposed that a 'pseudofertilization' took place when an irradiated nucleus penetrated the ovum. Transformation then occurred when fragments of the irradiated DNA were incorporated into the genome during a subsequent normal fertilization, effected by an unirradiated spermatozoon (Pandey, 1980; Pandey \& Patchell, 1982). This hypothesis was based on the observation that fowl spermatozoa retain some motility, assessed subjectively in vitro, after exposure to $1000 \mathrm{~Gy}$ of radiation (Pandey, 1980), and that following much lower doses ( $50 \mathrm{~Gy}$ ) many spermatozoa were capable of initiating abnormal development (Kosin, 1944).

The following work tests the validity of Pandey's hypothesis by a more rigorous assessment of sperm function both in vitro and in vivo.

\section{Materials and Methods}

Birds. Males and females were from a Rhode Island Red strain (Ross Poultry Ltd, Newbridge, Midlothian). They were caged individually, given $14 \mathrm{~h}$ light $/ 24 \mathrm{~h}$ and fed a commercial breeders ration ad libitum.

Semen collection and irradiation. Semen, free of transparent fluid, was collected twice each week according to the method of Lake (1957). Collections from 15-20 birds were pooled to give one sample. Each sample was diluted 2-fold in a glutamate-based diluent, $\mathrm{pH} 7 \cdot 1$ (Lake \& Ravie, 1979), and aliquants, one for each required dose of irradiation, were stored in sealed vials. These vials were transported to the radiation sources by placing them in a vacuum flask containing water at $5^{\circ} \mathrm{C}$. Gamma radiation was provided by two sources of different intensities. Source A was a point source delivering $0.055 \mathrm{~Gy} \mathrm{sec}^{-1}$ at the chosen locus ( $1 \mathrm{~Gy}=100 \mathrm{rads}$ ). This was used for doses of 50 to $200 \mathrm{~Gy}$, each dose ranging by $18 \%$ between the top and bottom of the sample. Source B was 
more active, delivering $0 \cdot 2 \mathrm{~Gy} \mathrm{sec}^{-1}$. This was used for doses of 300 to $700 \mathrm{~Gy}$. Dose variation within these samples was less than $0.1 \%$. Irradiation was performed at room temperature and all samples, including controls (no irradiation), were held at room temperature for the time taken for the maximum dose (60.3 min for Source A and $60 \mathrm{~min}$ for Source B). Samples were then replaced in the flask at $5^{\circ} \mathrm{C}$ for the return journey. The total time in transit was $25 \mathrm{~min}$ and $40 \mathrm{~min}$ for the journeys to Sources A and B, respectively.

In-vitro semen tests. Motility was determined by a light-scattering method relying on the rheotactic and optically anisotropic properties of spermatozoa (Wishart \& Ross, 1985). Motility was expressed as the constant ' $\%(\Delta \mathrm{OD})_{\mathrm{m}}$ ', which defines the maximum percentage fall in absorbance after stopping the movement of a suspension of spermatozoa through a flow-cell. This has been correlated with the percentage of motile fowl spermatozoa in diluted samples of semen (Wishart \& Ross, 1985).

Sperm ATP concentrations were determined in boiled extracts using firefly luciferase (Wishart, 1982).

Sperm morphology was assessed by light microscopic appearance of spermatozoa as smears stained with nigrosin and eosin (Lake \& Stewart, 1978).

Counting of spermatozoa trapped in the vitelline membrane. A square of vitelline membrane (2-3 cm per side) was removed from around the germinal disc area of eggs. This was then rinsed in $\mathrm{Ca}^{2+}-, \mathrm{Mg}^{2+}$-free Dulbecco's phosphate-buffered saline (PBS) (Dulbecco \& Vogt, 1954) and spread on a glass microscope slide. The preparation was stained in situ by adding a few drops of a $1 \mu \mathrm{g} / \mathrm{ml}$ solution of 4,6-diamidino-2-phenylindole (DAPI), covered with a coverslip and sealed with nail varnish. The blue-fluorescing, comma-shaped nuclei were then examined by fluorescence microscopy between 1 and $3 \mathrm{~h}$ after staining. Numbers of spermatozoa in an area of $5.49 \mathrm{~mm}^{2}$ were counted by scanning a $1 \mathrm{~cm}$-wide gap, delineated with a marker pen, on the slide.

Counting embryonic cells. The vitelline membranes surrounding the yolk was cut in a $1 \mathrm{~cm}$-diameter circle around the germinal area. The whole germinal area was then scooped out with a small spoon and made up to a $1 \mathrm{ml}$ volume with PBS and $1 \%$ Triton X-100. This was dispersed with a glass-Teflon homogenizer and the resulting sample was diluted 2-fold with a solution of $1 \mu \mathrm{g}$ $\mathrm{DAPI} / \mathrm{ml}$ in PBS. Stained samples were transferred to a haemocytometer and the rounded somatic nuclei were observed by fluorescence microscopy. Numbers were counted by scanning the full $7 \mathrm{~mm}$ well of the haemocytometer with a $0.55 \mathrm{~mm}$ diameter microscope field, i.e. cells within a total volume of $3.9 \mu$ l were counted.

Fertility testing. Of 2 -fold diluted semen, $0 \cdot 1 \mathrm{ml}$ containing about $200 \times 10^{\circ}$ spermatozoa was inseminated intravaginally into groups of randomly-selected hens. Fertility was assessed by candling with a fibre optic light source after 7 days of incubation. Apparently infertile eggs or those showing abnormal embryonic development were broken open for further examination.

With the unincubated eggs used for counting embryonic cells and spermatozoa caught in the vitelline membrane, 'fertility' was assessed by a macroscopic observation of the germinal area (Kosin, 1945).

Examination of utero-vaginal sperm-host glands. Longitudinal strips $(5 \times 1 \mathrm{~cm})$ were cut from the dorsal side of the oviduct to include the utero-vaginal junction as well as some vaginal and shellgland tissue. These were fixed in buffered formalin, embedded in paraffin wax and 6- $\mu \mathrm{m}$ sections were cut lengthwise. The numbers of sections of sperm-host glands in such preparations have been shown to be representative of the whole utero-vaginal area (Van Krey, Siegel \& Leighton, 1971). Sections were stained with haematoxylin and eosin. Starting from the vaginal side, sections of glands in 5 mucosal folds were assessed for the presence or absence of spermatozoa. 


\section{Results}

Spermatozoa were irradiated on two separate occasions, each with different semen samples and caesium sources. This was necessary since it was impractical to obtain lower doses of irradiation with the more active source, and preliminary studies showed that semen held for more than $1 \mathrm{~h}$ at room temperature tended to deteriorate. The effects of irradiation on sperm function in vitro were compared by describing values as a percentage of control values (Text-fig. 1). Sperm function values in control samples from the two treatments were different: the ATP content (nmol/10 ${ }^{9}$ spermatozoa), motility $\left(\%(\Delta O D)_{m}\right)$ and morphology (\% normal) were respectively $44 \cdot 9,0.75$ and 88 , for Source A controls and $39 \cdot 1,0.58$ and 88 for Source B controls.
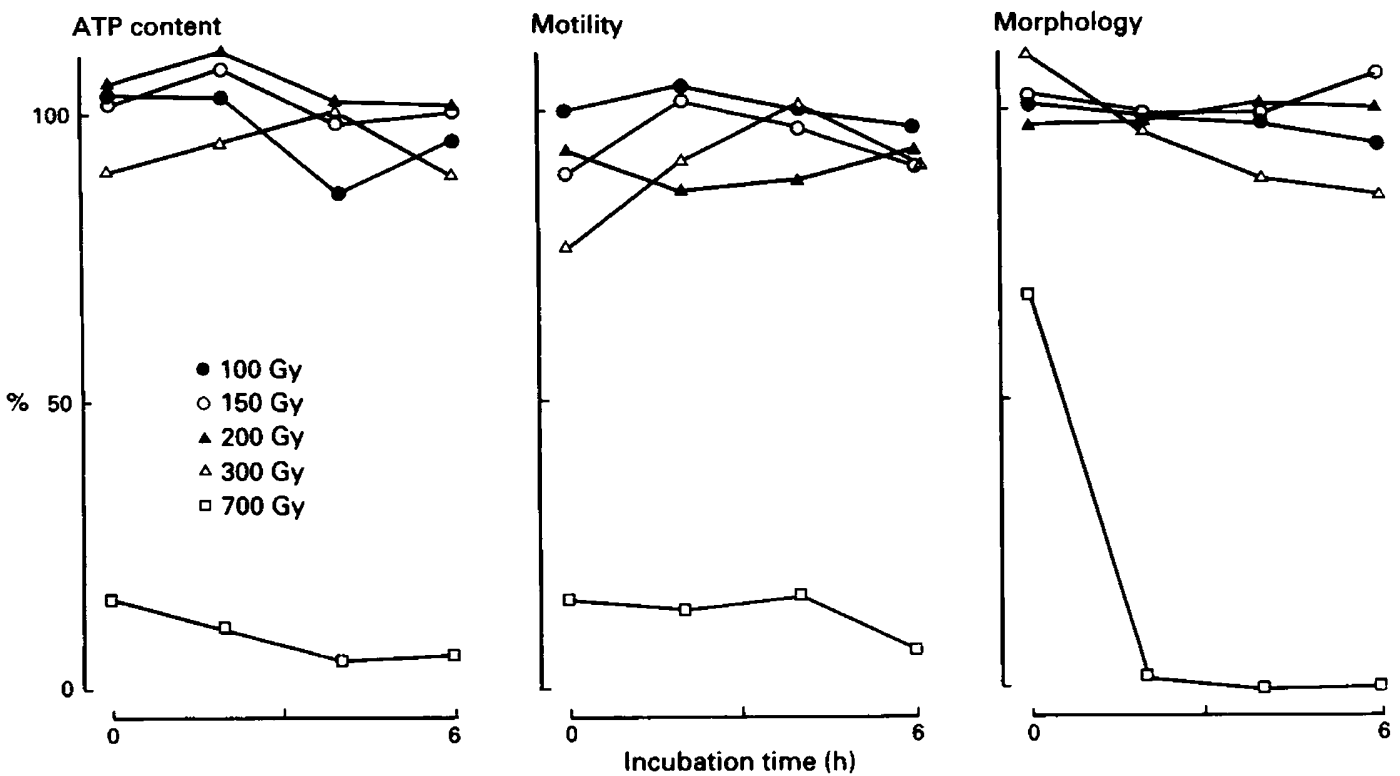

Text-fig. 1. The effect of irradiation on sperm function in vitro. Samples of fowl semen were divided into aliquants, diluted, irradiated and subsequently incubated aerobically at $40^{\circ} \mathrm{C}$.

Each point represents the mean of two estimates.

Of 65 eggs laid by hens during 1 week after insemination with semen treated with 50 Gy irradiation, 2 eggs showed postoviducal growth during incubation for 1 week (Text-fig. 2). One had developed as far as the formation of blood islands (approximately $30 \mathrm{~h}$ ), the other was the size of a 4-day embryo but had severe abnormalities.

Histological examination of the sperm-host glands showed that those taken 2 and $4 \mathrm{~h}$ after insemination with control spermatozoa had many spermatozoa in the uterine mucosa as well as in the sperm-host glands. These were not found in preparations from hens inseminated with spermatozoa irradiated with 300 Gy (Table 1).

Irradiated spermatozoa incubated in vitro for $4 \mathrm{~h}$ were indistinguishable from control spermatozoa when stained with haematoxylin and eosin or DAPI.

\section{Discussion}

Kosin (1944), Sarvella (1971) and Pandey (1980) found that the motility of irradiated fowl spermatozoa declined, with respect to control unirradiated samples, at doses greater than 85,100 


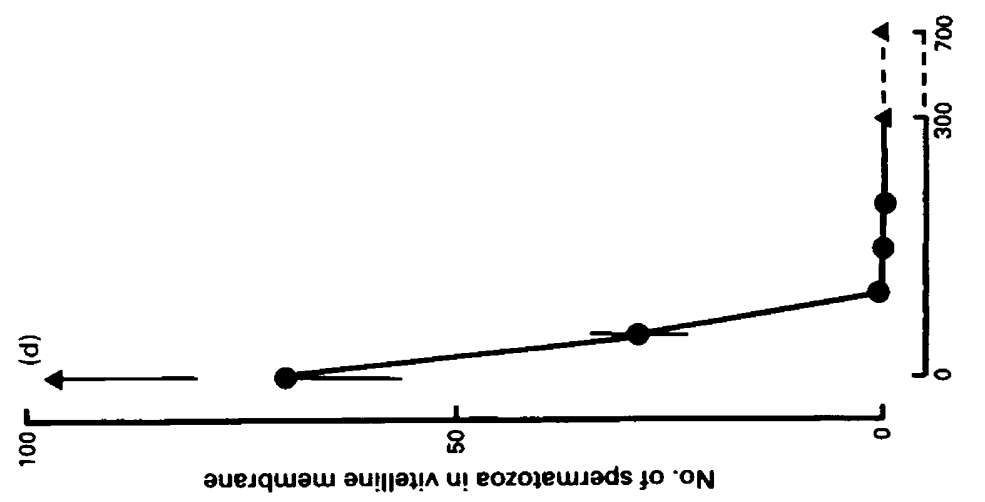

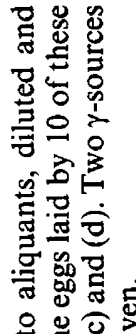

跑施

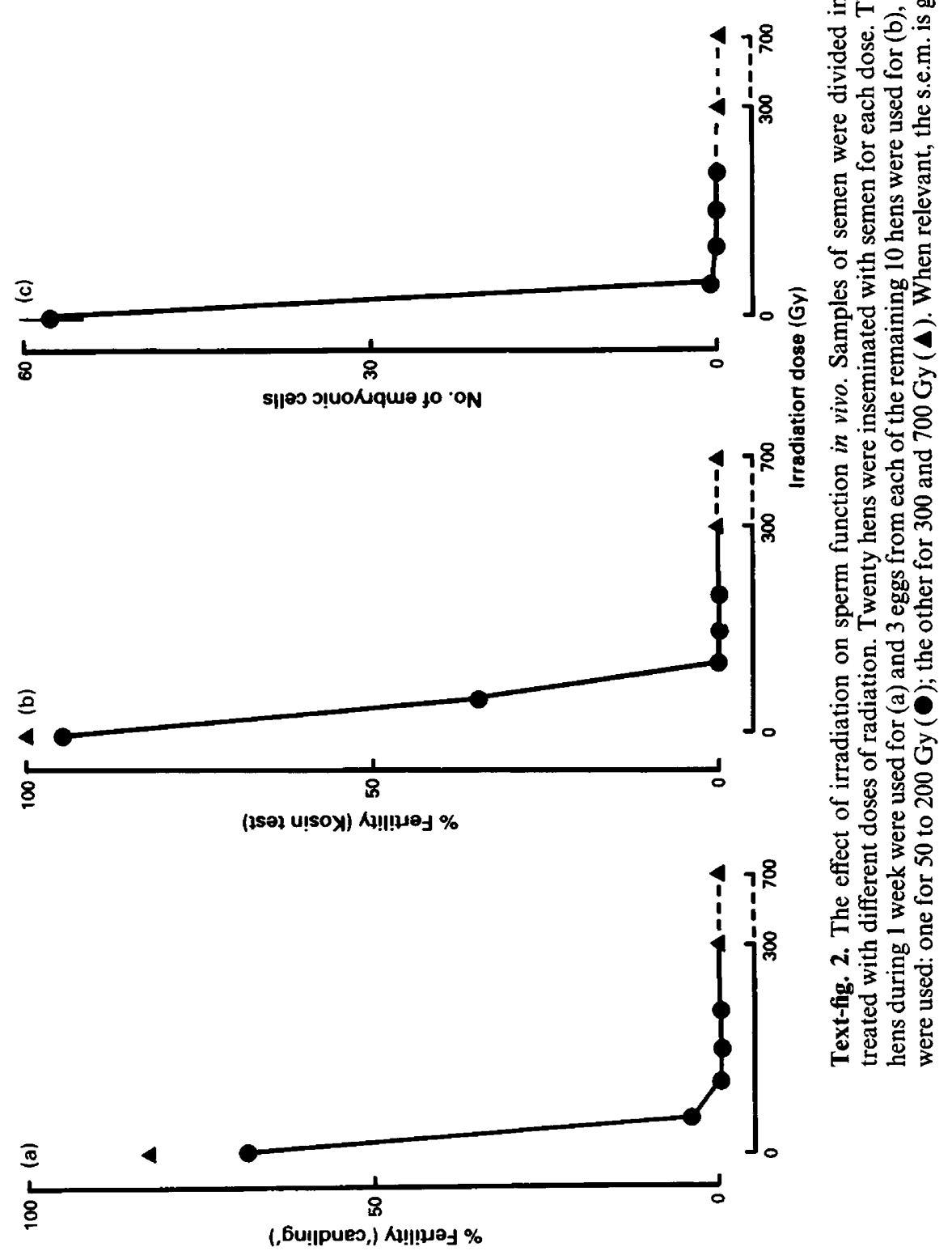


Table 1. Status of the utero-vaginal sperm-host glands after insemination with control and irradiated fowl spermatozoa

\begin{tabular}{lcccc}
\hline $\begin{array}{l}\text { Time after } \\
\text { insemination } \\
\text { (h) }\end{array}$ & $\begin{array}{c}\text { Irradiation } \\
\text { dose } \\
\text { (Gy) }\end{array}$ & $\begin{array}{c}\text { Bird } \\
\text { no. }\end{array}$ & $\begin{array}{c}\text { Total no. of } \\
\text { glands counted }\end{array}$ & $\begin{array}{c}\text { \% of glands } \\
\text { containing } \\
\text { spermatozoa }\end{array}$ \\
\hline 2 & 0 & 1 & 113 & 87 \\
2 & 300 & 1 & 112 & 79 \\
& & 2 & 68 & 0 \\
4 & 0 & 1 & 55 & 0 \\
& & 2 & 204 & 89 \\
4 & 300 & 1 & 61 & 90 \\
& & 2 & 131 & 0 \\
24 & 0 & 1 & 179 & 0 \\
& & 2 & 50 & 46 \\
& & 3 & 65 & 46 \\
24 & 4 & 63 & 54 \\
& 300 & 1 & 101 & 0 \\
& & 2 & 71 & 0 \\
24 & & 3 & 69 & 0 \\
& & 4 & 64 & 0 \\
& & 1 & 56 & 0 \\
& & 2 & 84 & 0 \\
\hline
\end{tabular}

and $250 \mathrm{~Gy}$, respectively. Our results (Text-fig. 1b) showed that the motility of irradiated spermatozoa was unaffected at doses of up to $300 \mathrm{~Gy}$. It is unlikely that our method of measuring motility is less sensitive because the above authors used a subjective microscopic 'scoring' method of motility estimation. More probably these differences reflect variable 'qualities' of semen: less vigorous spermatozoa from a highly inbred strain showed reduced activity after 300 Gy irradiation (G. J. Wishart, unpublished results). In the present work a dose of $700 \mathrm{~Gy}$ markedly reduced the motility, ATP content and morphology of spermatozoa measured in vitro. Since these characteristics have been correlated with the fertilizing ability of spermatozoa from individual males (Wishart \& Palmer, 1985) it is unlikely that spermatozoa treated with the higher dose of irradiation would function 'normally' in vivo.

Normal embryos did not develop in eggs from hens inseminated with spermatozoa which had received the low dose of $50 \mathrm{~Gy}$ and at higher doses all eggs were infertile (Text-fig. 2a). These results agree with the work of Kosin (1944).

Following insemination after treatment with doses in excess of $100 \mathrm{~Gy}$, no spermatozoa were found in the vitelline membranes from 107 eggs (Text-fig. 2d). With control semen, a total of 3768 spermatozoa were counted in membranes from 52 eggs. Since the secondary vitelline membrane, in which spermatozoa become caught (Bakst \& Howarth, 1977), forms in the infundibulum directly after fertilization (Bain \& Hall, 1969) it may be assumed that the irradiated spermatozoa did not reach the ovum. In fact, after irradiation with doses of 300 and $700 \mathrm{~Gy}$, spermatozoa seem incapable of reaching as far as the utero-vaginal sperm-host glands which are recognized as the main oviducal storage site for fowl spermatozoa (Bobr, Lorenz \& Ogasawara, 1964). Since spermatozoa could also be found lining the mucosal region of the utero-vaginal junction after insemination with control, but not $300 \mathrm{~Gy}$-irradiated, semen, they probably do not even enter the uterus. Such irradiated spermatozoa, however, remain vigorously motile and appear normal for $6 \mathrm{~h}$ in vitro (Text-fig. 1). Presumably these spermatozoa can be discriminated and perhaps immobilized in the vagina. 
How do these findings reconcile with published effects of irradiated spermatozoa on the development of eggs laid by inseminated hens? Irradiated spermatozoa have been reported to cause an increase in parthenogenetic membrane development $(200 \mathrm{~Gy}$ : Sarvella, 1971) and to effect genetic transformation by 'pseudofertilizing' eggs (750 Gy: Pandey, 1980; Pandey \& Patchell, 1982). Physiologically, these reports are justified on the basis of the measurement of sperm motility in vitro and on an extrapolation of the findings of Kosin (1944), that spermatozoa dosed with $50 \mathrm{~Gy}$ reach the ovum efficiently, to higher doses. The present results show that neither premise is justified. Other explanations of how their results were achieved are beyond the scope of this work.

Ova from hens inseminated with $50 \mathrm{~Gy}$-dosed spermatozoa were clearly surrounded by significant numbers of spermatozoa at the time of normal fertilization, as indicated by those trapped in the vitelline membrane (Text-fig. 2d). However, these ova showed little sign of development, most having negligible numbers of embryonic nuclei (Text-fig. 2c) although $35 \%$ of the germinal discs of laid eggs did not have the lacunae (Text-fig. $2 \mathrm{~b}$ ) which are typical of degenerating infertile ova (Kosin, 1945). If degeneration of these 'ova' had been arrested, it might have resulted from penetration by an irradiated spermatozoon. Therefore, if irradiated spermatozoa are to be used as vectors for genetic transformation, then $50 \mathrm{~Gy}$ may be an appropriate dose to use.

We thank Miss F. Palmer for skilled assistance, Mr K. Ramage of Ethicon Ltd, Edinburgh and Dr H. Fraser of the AFRC/MRC Neuropathogenesis Unit, Edinburgh, for irradiating semen samples, and Dr J. Mckay for helpful discussion.

\section{References}

Bain, J.M. \& Hall, J.M. (1969) Observations on the development and structure of the vitelline membrane of the hens eggs: an electron microscope study. Aust. J. biol. Sci. 22, 653-665.

Bakst, M.R. \& Howarth, B. (1977) Hydrolysis of the hen's perivitelline layer by cock sperm in vitro. Biol. Reprod. 17, 370-379.

Bobr, L.W., Lorenz, F.W. \& Ogasawara, F.X. (1964) Distribution of spermatozoa in the oviduct and fertility in domestic birds. 1. Residence sites of spermatozoa in fowl oviducts. J. Reprod. Fert. 8, 39-47.

Dulbecco, R. \& Vogt, M. (1954) Plaque formation and isolation of pure lines with poliomyelitis viruses. $J$. exp. Med. 99, 167-199.

Kosin, I.I. (1944) Some aspects of the biological action of $\mathrm{x}$-rays on cock spermatozoa. Physiol. Zool. 17, 289-319.

Kosin, I.I. (1945) The accuracy of the macroscopic method in identifying fertile unincubated germ discs. Poult. Sci. 24, 281-295.

Lake, P.E. (1957) Fowl semen as collected by the massage method. J. agric. Sci., Camb. 49, 120-126.

Lake, P.E. \& Ravie, O.R. (1979) Effect on fertility of storing fowl semen for $24 \mathrm{~h}$ at $5^{\circ} \mathrm{C}$ in fluids of different pH. J. Reprod. Fert. 57, 149-155.

Lake, P.E. \& Stewart, J.M. (1978) Artificial insemination in poultry. Bull. Min. Ag., Fish. Food, No. 213. H.M.S.O., London.
Pandey, K.K. (1980) Resistance of male gamete function to ionising radiation: implications in evolution and in induced transformation in higher organisms. N.Z. $J l$ Sci. 23, 361-364.

Pandey, K.K. \& Patchell, M.R. (1982) Genetic transformation in chicken by the use of irradiated male gametes. Molec. gen. Genet. 186, 305-308.

Sarvella, P. (1971) Frequency of parthenogenesis in chickens after insemination with irradiated sperm. Radiat. Res. 46, 186-191.

Van Krey, H.P., Siegel, P.B. \& Leighton, A.T. (1971) Repeatability estimates and quantification of utero-vaginal sperm host gland numbers and population patterns. Biol. Reprod. 4, 31-34.

Wishart, G.J. (1982) Maintenance of ATP concentrations in and of fertilizing ability of fowl and turkey spermatozoa in vitro. J. Reprod. Fert. 66, $457-462$.

Wishart, G.J. \& Palmer, F.H. (1985) Correlation of the fertilising ability of semen from individual male fowls with sperm motility and ATP content. Br. Poult. Sci. (in press).

Wishart, G.J. \& Ross, F.H. (1985) Characterisation of a spectrophotometric technique for the estimation of fowl and turkey sperm motility. Gamete Res. 11, 169-178.

Received 29 April 1985 